\title{
Englacial seismic reflectivity: imaging crystal-orientation fabric in West Antarctica
}

\author{
Huw J. HORGAN, ${ }^{1,2}$ Sridhar ANANDAKRISHNAN, ${ }^{2,3}$ Richard B. ALLEY,, 3 \\ Peter G. BURKETT, ${ }^{2,3}$ Leo E. PETERS 2,3 \\ ${ }^{1}$ Antarctic Research Centre, Victoria University of Wellington, PO Box 600, Wellington, New Zealand \\ E-mail: huw.horgan@vuw.ac.nz \\ ${ }^{2}$ Department of Geosciences and PSICE Center, The Pennsylvania State University, University Park, \\ Pennsy/vania 16802-7501, USA \\ ${ }^{3}$ Earth and Environmental Systems Institute, The Pennsylvania State University, University Park, \\ Pennsy/vania 16802-2711, USA
}

\begin{abstract}
Abrupt changes in crystal-orientation fabric (COF), and therefore viscosity, are observed near the base of the ice sheet throughout West Antarctica. We report on active-source seismic observations from WAIS Divide, mid-stream and downstream on Thwaites Glacier, and the onset region of Bindschadler Ice Stream. These data reveal a prevalence of englacial seismic reflectivity in the bottom quarter of the ice sheet. The observed seismic reflectivity is complex but largely bed-conformable, with long-spatial-wavelength features observed in the flow direction and short-wavelength features observed across flow. A correspondence of englacial structures with bed features is also observed. We determine the origin of the reflectivity to be abrupt changes in the COF of ice, based on the following: (1) observations of englacial reflectivity are consistent with current knowledge of COF within ice sheets, (2) englacial reflectivity caused by COF contrasts requires the simplest genesis, especially at ice divides, and (3) amplitude analysis shows that the observed englacial reflectivity can be explained by contrasts in seismic velocity due to COF changes. We note that the downstream increase in the quantity and complexity of observations indicates that direct observations of COF at ice divides likely underestimate the role that fabric plays in ice-sheet dynamics.
\end{abstract}

\section{INTRODUCTION}

Flow in the interior of ice sheets is dominated by internal deformation, during which dislocation glide occurs between the basal planes of the ice crystal. Deformation parallel to the basal plane is at least an order of magnitude easier to achieve than perpendicular to it (Hobbs, 1974). This dependence of viscosity on orientation leads to the evolution of crystal-orientation fabrics (COFs) with deformation, and makes knowledge of COF important for our understanding of ice-sheet dynamics. The distribution of direct observations of COF in polar regions is biased towards the ice-sheet interiors and ice divides, where measurements are routinely made during ice-core studies (e.g. Gow and Williamson, 1976; Gow and others, 1997; Thorsteinsson and others, 1997; Gow and Meese, 2007b). Typically, ice-divide observations show nearly randomly distributed $c$-axis orientations in the near surface. (Crystal orientations are commonly referenced to the $c$-axis, which is perpendicular to the basal plane, or the distribution of $c$-axes on a lower-hemisphere Schmidt projection.) With increasing depth, the $c$-axes rotate towards the vertical due to vertical compression or simple shear. At even greater depths, and if conditions favor recrystallization, newly formed crystals may result in the return of a dispersed distribution. There are fewer direct COF observations away from the main ice divides of the large ice sheets; however, those that do exist (e.g. Law Dome, East Antarctica (RussellHead and Budd, 1979; Budd and Jacka, 1989); Barnes Ice Cap, Baffin Island, Canada (Hooke, 1973)) show COF profiles generally similar to those observed at divides, but with some evidence for fabric evolution along flow. (For a comprehensive review see Budd and Jacka, 1989, and references therein.) Laboratory studies confirm that COF evolves during deformation (e.g. Rigsby, 1958; Budd and Jacka, 1989; Wilson and others, 2003). For example, Budd and Jacka (1989), starting with isotropic ice, applied different stress regimes to reproduce COF distributions observed in the field, demonstrating that unconfined vertical compressive stress results in $\mathrm{C}$-axis orientations that are distributed about the vertical in either a girdled or distributed cone. Confined compression resulted in a two-maxima fabric, while simple shear results in a strong single-maximum fabric. These findings generally agree with theoretical simulations (Alley, 1988; Van der Veen and Whillans, 1994).

Geophysical methods for measuring COF in ice include radio-echo sounding, direct ultrasonic methods and surfacebased active-source seismology. In East Antarctica, Fujita and others (1999) used the different frequency responses of radar reflectivity to contrasts in dielectric permittivity and electrical conductivity in a study between Dome Fuji and the East Antarctic coast. Using a dual-frequency radar, they were able to distinguish between permittivity-induced COF reflectivity and reflectivity due to acidity-induced conductivity changes. Matsuoka and others (2003) combined dual-frequency and multipolarization radar techniques to infer layered single-pole and vertical-girdle COFs in a similar transect from Dome Fuji towards the Antarctic coast. Also in East Antarctica, Eisen and others (2007) correlate an airborne radio-echo sounding return with an abrupt change in COF observed in the EPICA (European Project for Ice Coring in Antarctica) core. In contrast, ultrasonic borehole, core and surface seismic methods utilize the seismic anisotropy of ice, whereby sound waves travel faster along the 


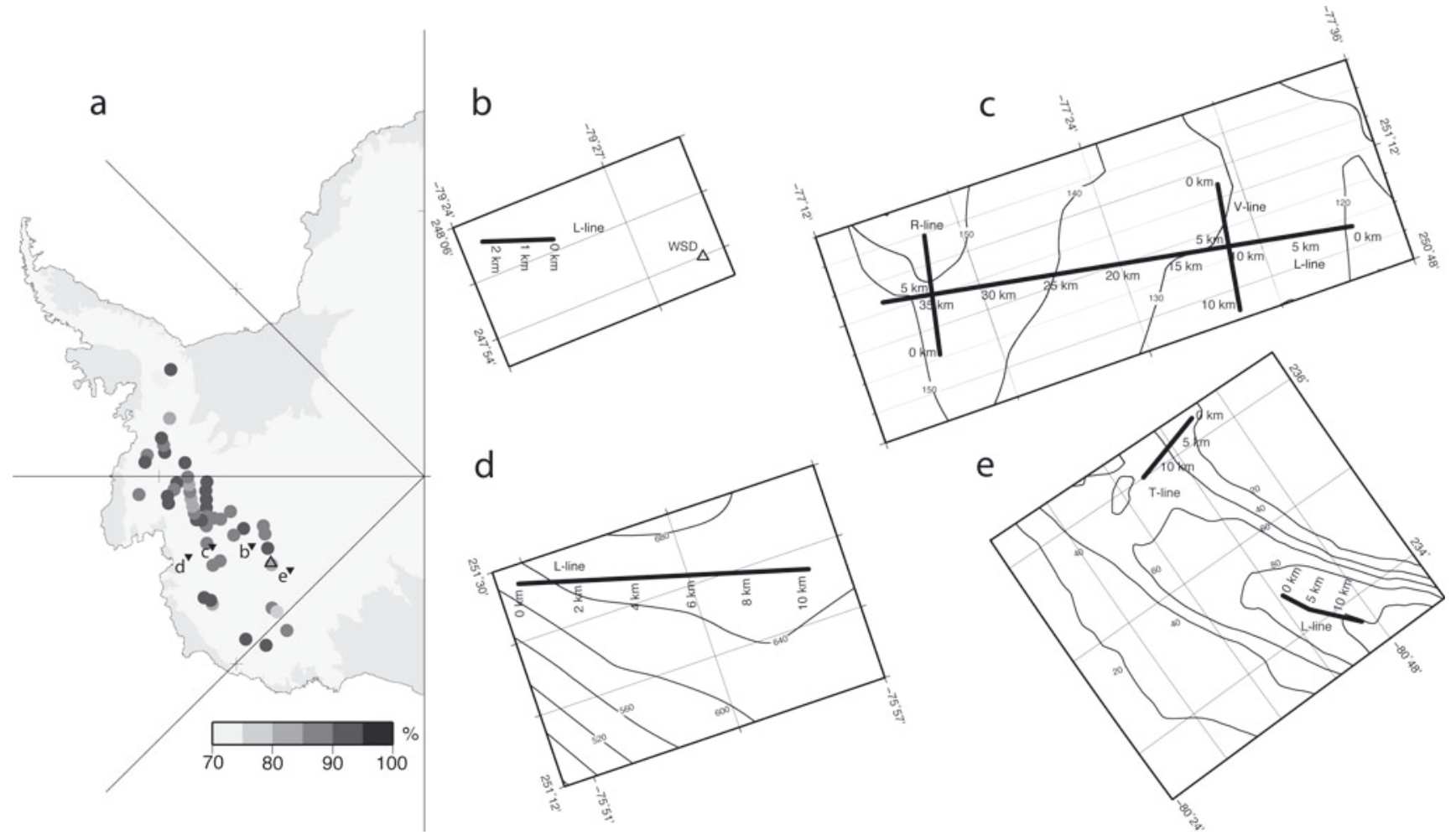

Fig. 1. (a) Location map showing study locations in West Antarctica. The grayscale filled circles denote percentage thicknesses for the englacial reflectivity, $R_{\mathrm{E}}$, reported by Bentley (1971b). Coastline and grounding line from the Moderate Resolution Imaging Spectroradiometer (MODIS) Mosaic of Antarctica (MOA; T. Haran and others, http://nsidc.org/data/nsidc-0280.html), 2005. Inverted triangles (b-e) denote the seismic reflection profiles reported in this study, all of which have corresponding maps on the right. The empty triangle denotes the deep ice core at Byrd Camp. (b) WAIS Divide profile location. Triangle labeled WSD denotes the location of the WAIS Divide deep ice core. Velocities in this area are $<10 \mathrm{~m} \mathrm{a}^{-1}$ (Conway and Rasmussen, 2009). (c) Up-Thwaites profile locations. (d) Down-Thwaites profile location. (e) Onset-D profile locations. Contours in (c-e) show ice velocities in $\mathrm{m} \mathrm{a}^{-1}$ (personal communication from I. Joughin, 2008). Note the difference in scales and contour intervals.

C-axis than perpendicular to it (Bennett, 1968; Röthlisberger, 1972). Ultrasonic methods have been used to determine COF in boreholes and ice cores. Bentley and Clough (1972) logged the first $1550 \mathrm{~m}$ of the $2164 \mathrm{~m}$ Byrd Station borehole and showed good correlation with measured compressional wave velocity, $V_{\mathrm{p}}$, and velocities calculated from direct COF observations from the core. Similarly, Herron and others (1982) measured vertical and horizontal $V_{p}$ on samples from Greenland's Dye-3 ice core, and showed a quantitative correlation between the $c$-axis distribution and the difference between the vertical and horizontal $V_{\mathrm{p}}$. (Notably, Herron and others (1985) also observed a vertical $V_{p}$ increase of $167 \mathrm{~m} \mathrm{~s}^{-1}$ over a $10 \mathrm{~m}$ interval $\sim 200 \mathrm{~m}$ above the base of the ice sheet.) Anandakrishnan and others (1994) expanded on the ultrasonic method by using shear waves as well as compressional waves in a study of COF of the GISP2 (Greenland Ice Sheet Project 2) core. By combining these two wave types, they were able to calculate a degree of obliquity of the COF cone.

Surface-based seismic methods, while having the advantage of not requiring a core or borehole, suffer from reduced resolution and lack associated measurements for comparison. Bentley (1971a) used seismic reflection data, and the azimuthal dependence of velocity from refraction data, to estimate the degree and orientation of anisotropy in West Antarctica. He noted that away from divides COFs were often aligned in the direction of flow and suggested a proportionality between the inclination of COF cones and the longitudinal strain rate. Blankenship and Bentley (1987) used travel times from intersecting wide-angle seismic profiles near Dome $\mathrm{C}$ to infer a vertical anisotropic axis of symmetry resulting from a range of possible $c$-axis distributions with depth. In Greenland, Horgan and others (2008) reported englacial seismic reflectivity from upstream on Jakobshavn Isbræ, where the englacial reflectivity was attributed to contrasts in COF. The most extensive dataset of englacial seismic reflectivity to date was acquired in the Antarctic during the late 1950s and early 1960s. Researchers using seismic methods for depth sounding noted the persistent presence of a weak englacial reflection (e.g. Bentley and Ostenso, 1961). The englacial reflection, $R_{\mathrm{E}}$, commonly occurred a few hundred meters above the bed and had an amplitude approximately a tenth the strength of the bed reflection (Bentley, 1971b). Bentley (1971b) compiled observations of englacial reflectivity in West Antarctica (Fig. 1), and using amplitude analysis and observations of return characteristics argued that the cause of the reflection was entrained morainal material. He eliminated a COF explanation based on the reverberatory nature of the return and insufficient impedance contrast from anisotropy-generated velocity contrasts. Subsequent seismic studies in polar regions have attributed englacial reflectivity to either entrained basal material (Smith, 1996), or contrasts in $C$-axis orientation (Anandakrishnan, 1996; Smith, 1996; Horgan and others, 2008).

Here we present high-resolution active-source seismic observations from West Antarctica. These data are significant in two respects. Firstly, they provide high-resolution images of englacial structures deep within polar ice, where 
Table 1. Seismic acquisition parameters

\begin{tabular}{|c|c|c|c|c|c|c|c|}
\hline \multirow[t]{2}{*}{ Location/line } & \multirow[t]{2}{*}{ Season } & \multirow{2}{*}{$\begin{array}{c}\text { Source size } \\
\text { kg }\end{array}$} & \multirow{2}{*}{$\begin{array}{c}\text { Source } z \\
\text { m }\end{array}$} & \multirow{2}{*}{$\begin{array}{c}\text { Source } \delta x \\
\text { m }\end{array}$} & \multirow[t]{2}{*}{$\begin{array}{l}\text { Number of } \\
\text { receivers }\end{array}$} & \multirow{2}{*}{$\begin{array}{c}\text { Receiver type } \\
\text { z } \\
\mathrm{Hz}\end{array}$} & \multirow{2}{*}{$\begin{array}{c}\text { Receiver } \delta x \\
\mathrm{~m}\end{array}$} \\
\hline & & & & & & & \\
\hline Up-Thwaites & 2008/09 & 0.4 & 45 & 480 & 48 & 28 & 20 \\
\hline Down-Thwaites & $2007 / 08$ & 0.4 & 20 & 480 & 48 & 28 & 20 \\
\hline Onset-D & 2003/04 & 0.4 & 60 & 300 & 120 & 100 & 10 \\
\hline WAIS Divide & 2008/09 & 0.4 & 24 & 480 & 48 & 28 & 20 \\
\hline
\end{tabular}

radio-echo sounding techniques often see only the bed. Secondly, the seismic reflection is directly and simply related to the difference in acoustic properties occurring across the reflection horizon, making the origin and importance of the observations tractable. We show that the structures imaged here most likely result from contrasts in COF, and discuss the importance of these observations for ice-sheet dynamics. Our methods are akin to those used by Smith (1996) and are the modern equivalent of the methods of Bentley (1971b). As such, they are distinct from ultrasonic studies (e.g. Bentley and Clough, 1972; Herron and others, 1985) and the refraction seismic techniques used by Bentley (1971a), which all measure velocity. As the seismic reflection technique used here images contrasts in acoustic properties, it is sensitive to contrasts in COF, as opposed to the fabric strength. Our findings, therefore, pertain more to the degree of changes in the fabric pattern in ice sheets than the fabric strength itself.

\section{DATA ACQUISITION AND PROCESSING}

Oversnow active-source seismic surveying uses land-based techniques, with modifications to suit the environment. (Reviews of active-source seismic methods for glaciological applications are given by Röthlisberger (1972), Smith (2007) and Holland and Anandakrishnan (2009).) While the acquisition parameters varied between the surveys reported here (Table 1), the principles were common to all datasets. Seismic profiles were surveyed using kinematic GPS, traditional surveying and electronic distance measuring. The source consisted of an explosive composed mainly of PETN (pentaerythritol tetranitrate) detonated at depth. The shot depth was ideally determined by the density profile but was sometimes limited by drilling capabilities. The receivers were single-component vertical geophones with natural frequencies of 28, 40 or $100 \mathrm{~Hz}$. The geophones were buried at shallow depths of up to $0.5 \mathrm{~m}$ to reduce wind noise. Synchronization between the seismic digitizer and the shot triggering was achieved by GPS time signals. Data sampling rates met or exceeded $1000 \mathrm{~Hz}$. Our resolution is determined by the wavelength of our data. At the upper limit, frequencies of $200 \mathrm{~Hz}$ result in vertical resolutions of $\sim 5 \mathrm{~m}$, and horizontal resolutions at $2 \mathrm{~km}$ depth of $\sim 280 \mathrm{~m}$. Depth uncertainties, which are largely composed of uncertainties in the velocity model and picking errors, are approximately $\pm 30 \mathrm{~m}$ at the glacier bed.

Data processing followed land-based techniques, with special attention paid to processes that provide improvements to oversnow data, such as deconvolution and static corrections. Two processing routines were used. The first was intended to maximize imaging potential, while the second preserved true amplitudes for subsequent analysis.
Processing can be divided into pre-stack and post-stack steps. Pre-stack processing began with the editing of noisy or otherwise bad traces, data despiking and frontal muting of direct arrivals (Yilmaz, 1987). Shot data were then bandpassand frequency/wavenumber-filtered. Static corrections were applied using surface elevations and a stack-power algorithm (Ronen and Claerbout, 1985). A two-step deconvolution technique was used to first compress the source wavelet and then to suppress the ghost arrival resulting from the burial of the shot beneath the surface. Prior to stacking, shot data were sorted into common depth point gathers and a normal moveout correction was applied using velocities estimated from constant velocity stacks with a firn velocity model applied. Stacked data were migrated and a post-stack deconvolution applied. The second processing routine preserved true amplitudes and consisted only of noise editing, static corrections and frequency filtering. After horizon digitizing, root-mean-square (rms) window amplitudes were calculated for subsequent analysis.

\section{PROFILE DATA}

Englacial reflectivity is high frequency $(>150-200 \mathrm{~Hz})$, continuous along profiles and traceable between intersecting profiles. The reflectivity is largely bed-conformable; long spatial wavelengths are observed along flow, and shorter spatial wavelengths are observed perpendicular to flow. After deconvolution to remove shot-signature effects, englacial reflectivity varies between a sharp onset single-pulse wavelet and a ringing wave packet. It is common to observe more than one englacial reflection event, and crosscutting structures are also observed. However, it is not possible to ascertain whether the cross-cutting events are caused by out-of-plane features or are representative of actual structure.

\section{WAIS Divide}

In February 2009 a short multichannel reflection profile was acquired near the West Antarctic ice sheet (WAIS) Divide drill site (Fig. 1b). To avoid the noise caused by drilling operations, the profile began $\sim 5 \mathrm{~km}$ from the core site, and extended $\sim 2.5 \mathrm{~km}$ along-flow towards the Walgreen Coast (Amundsen Sea sector). Due to the limitations of the small hot-water drill used, shots were placed at a relatively shallow depth in the firn column (Table 1). The data (Fig. 2) show an englacial reflection, $R_{\mathrm{E}}$, at $\sim 300 \mathrm{~m}$ above the bed, which is at $3209 \mathrm{~m}$ (Table 2). At the WAIS Divide drill site, the same percentage depth corresponds to $3130 \pm 30 \mathrm{~m}$. Based on proximity, we speculate that the transition will be similar to that found near the base of the Byrd core, i.e. a recrystallization boundary with a change from a fine-grained 


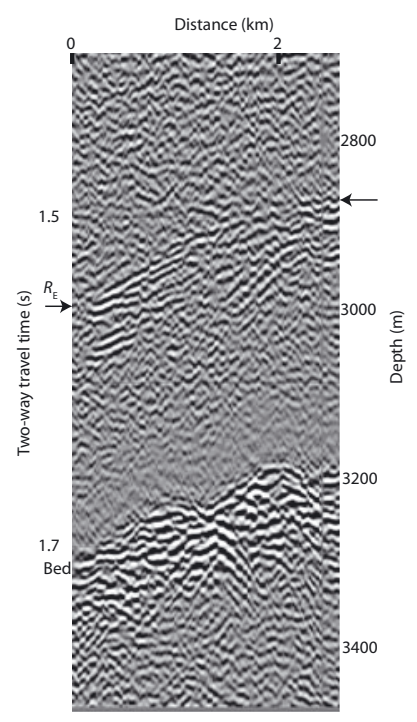

Fig. 2. WAIS Divide multichannel seismic profile (Fig. 1b; L-line for location). The englacial reflection, $R_{\mathrm{E}}$, is marked with horizontal arrows on the time and depth scales. The depth scale for this figure, and all subsequent seismic profiles, is approximated using a velocity of $3850 \mathrm{~m} \mathrm{~s}^{-1}$.

texture with a strong single-pole fabric to a coarse-grained texture with a distributed fabric (Gow and Williamson, 1976). Ice-core drilling at WAIS Divide is expected to penetrate this zone during the 2010/11 austral summer, and physical properties should be available thereafter.

\section{Up-Thwaites}

Active-source seismic profiles were acquired on Thwaites Glacier during the austral summers of 2007/08 and 2008/09, as part of a study of basal processes. In 2008/09 58 km of data were acquired along a $\sim 38 \mathrm{~km}$ long longitudinal line and along two $\sim 10 \mathrm{~km}$ long transverse profiles. The survey was designed to target a change in inferred basal drag (Joughin and others, 2009), with the longitudinal profile spanning the transition and each transverse profile corresponding to a region of low and high basal shear, respectively. The longitudinal profile (Fig. 3) displays continuous bedconformable englacial reflectivity throughout the profile. Englacial reflectivity begins at $\sim 2135 \pm 140$ m depth, which is $\sim 410 \mathrm{~m}$ above the bed at $2550 \pm 140 \mathrm{~m}$. In the upstream end of the profile, where low basal shear stress is estimated

Table 2. Average ice thickness and depth of the shallowest englacial reflection, $R_{\mathrm{E}}$. Values in parentheses represent the $1 \sigma$ distribution of the thicknesses

\begin{tabular}{lccc}
\hline Location, line & Depth to bed & Depth to $R_{\mathrm{E}}$ & $\begin{array}{c}\text { Percentage } \\
\text { depth to } R_{\mathrm{E}}\end{array}$ \\
& $\mathrm{m}$ & $\mathrm{m}$ & $\%$ \\
\hline WAIS Divide, L-line & $3209(35)$ & $2906(39)$ & 91 \\
Up-Thwaites, L-line & $2550(140)$ & $2135(140)$ & 84 \\
Up-Thwaites, V-line & $2626(116)$ & $2213(59)$ & 84 \\
Up-Thwaites, R-line & $2333(46)$ & $1902(27)$ & 82 \\
Down-Thwaites, L-line & $1864(23)$ & $1466(25)$ & 79 \\
Onset-D, L-line & $2077(90)$ & $1492(81)$ & 72 \\
Onset-D, T-line & $2061(131)$ & $1586(108)$ & 77 \\
& & & \\
\hline
\end{tabular}

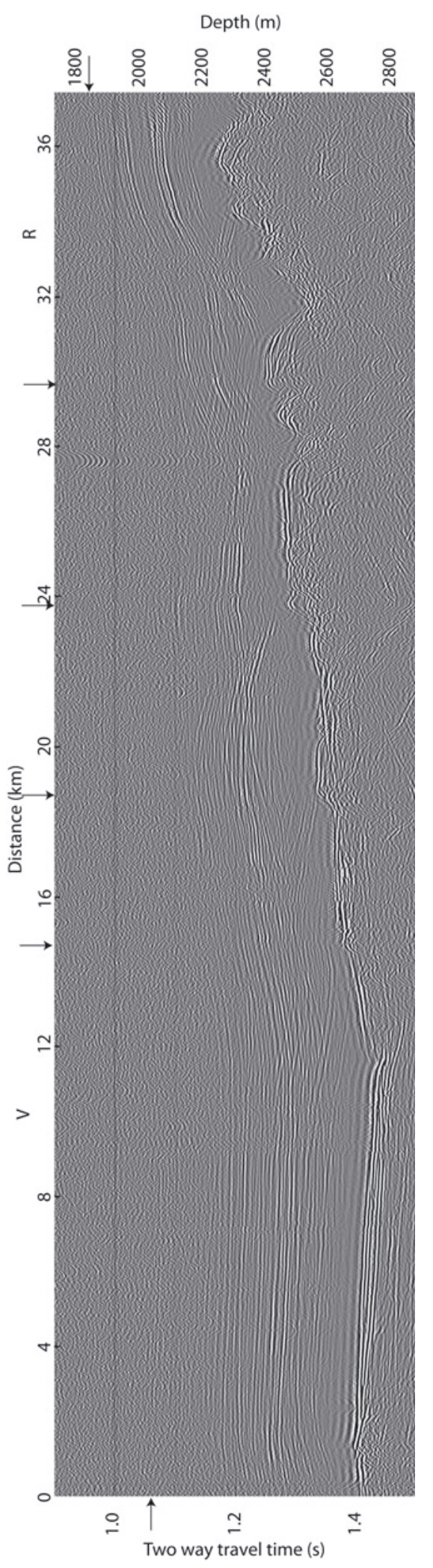

Fig. 3. Up-Thwaites longitudinal profile (Fig. 1c; L-line for location). Flow from left to right. The onset of englacial reflectivity is marked with horizontal arrows on the time and depth scales. The intersections with the V-line and R-line are marked with letters $\mathrm{V}$ and $\mathrm{R}$, respectively. Note that as the basal topography becomes more pronounced, the englacial reflectivity becomes more complicated with cross-cutting structures and greater relief. Note also the correspondence between pronounced bed topography and englacial structure. At locations where prominent bed features protrude upwards into the base of the ice, englacial reflectors are observed (e.g. see vertical arrows at kilometer marks 14.6, 18.8, 23.8, 29.6). 


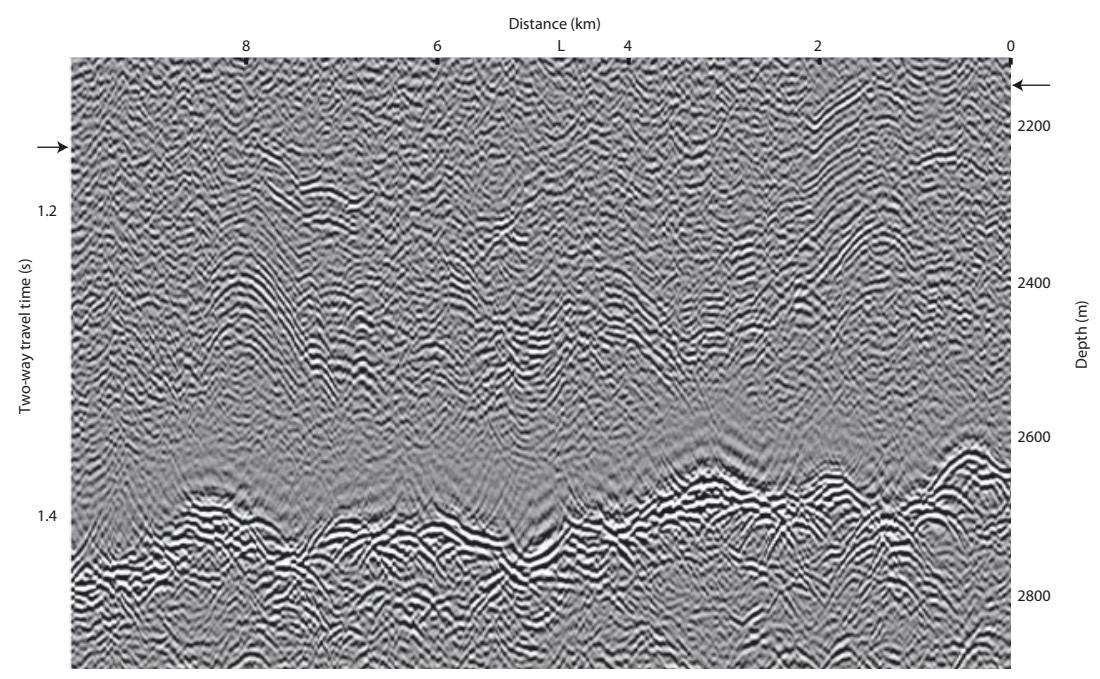

Fig. 4. Up-Thwaites upstream transverse profile (Fig. 1c; V-line for location). Flow into the page. The onset of englacial reflectivity is marked with horizontal arrows on the time and depth scales, and the intersection with the L-line is marked with the letter L. Note the shorter spatial wavelength of both the bed topography and the englacial topography than that observed in the longitudinal profile (Fig. 3). Note also the loose correlation of bed topography with topography on the englacial reflectors. Also, the bed topography is slightly more subdued in this upstream profile than in the downstream profile (Fig. 5).

(Joughin and others, 2009), the englacial reflectivity is flat-lying. As the basal topography becomes more pronounced, the englacial reflectivity becomes more complicated with cross-cutting structures and greater topography. There is also a correspondence between pronounced bed topography and englacial structure. At locations where prominent bed features protrude upwards into the base of the ice (e.g. Fig. 3 at kilometer marks 14.6, 18.8, 23.8, 29.6) englacial reflectors are observed. The englacial reflectors dip from upstream to downstream, with their downstream ends terminating at the bed features.

The transverse lines (Figs 4 and 5) display shorterwavelength bed topography. Topography on the englacial reflectivity is loosely bed-conformable. Bed relief is slightly more subdued in the upstream profile (Fig. 4) where englacial reflectivity begins at $\sim 410 \mathrm{~m}$ above the bed (at $84 \%$ of the ice thickness). In the downstream profile (Fig. 5) bed topography is slightly more pronounced, with englacial reflectivity observed to begin at $\sim 430 \mathrm{~m}$ above the bed at $82 \%$ of ice thickness.

\section{Down-Thwaites}

During the 2007/08 season, multichannel seismic data were acquired $\sim 60 \mathrm{~km}$ from the grounding line of Thwaites Glacier. The intent of this survey was to investigate the lithology of the grounding-line sill, with a view to determining its stability. The survey took place just landward of the sill due to heavy crevassing in the area and was oriented in such a way as to intersect the sill. The profile (Fig. 6) shows intense englacial reflectivity beginning at $\sim 400 \mathrm{~m}$ above the bed (79\% of the ice thickness). The englacial reflectors are only roughly bed-conformable, and many cross-cutting structures are evident. Radar profiling in the area imaged a complex bed topography, suggesting out-of-plane features may be responsible for some of the observed reflectivity.

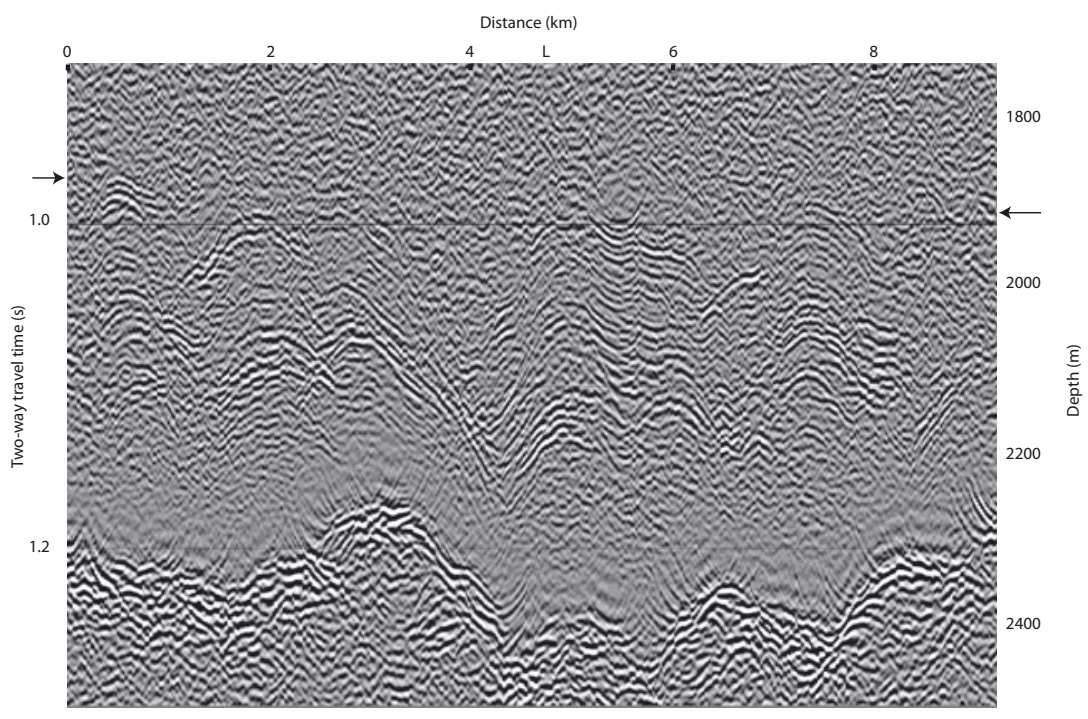

Fig. 5. Same as Figure 4, but for the downstream profile (Fig. 1c; R-line for location). 


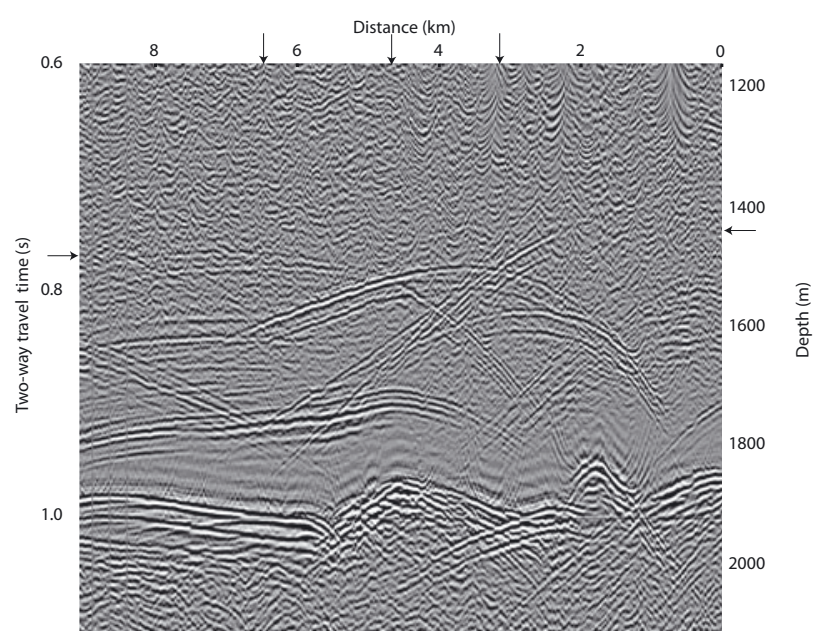

Fig. 6. Down-Thwaites longitudinal profile. Flow is from left to right with a component of flow out of the page (Fig. 1d; L-line for location). Intense englacial reflectivity is evident throughout the profile. The onset of englacial reflectivity is marked with horizontal arrows on the time and depth scales. In this profile, englacial reflectivity is loosely correlated with bed topography. Examples of cross-cutting features are evident and marked by vertical arrows on distance scale.

\section{Onset-D}

The Onset-D campaign acquired seismic data during the austral summer of 2003/04 at the onset region of Bindschadler Ice Stream. Data from this campaign have previously been used to address subglacial sediments (Peters and others, 2006) and subglacial water storage (Peters and others, 2007). The along-flow L-line (Fig. 7) is $\sim 14 \mathrm{~km}$ long and shows englacial reflectivity beginning at $590 \mathrm{~m}$ above the bed (72\% of ice thickness). Several distinct horizons are continuous for up to $\sim 5 \mathrm{~km}$ along the profile. The Lline also displays steeply dipping englacial reflectivity and cross-cutting reflectivity. Ghosting is apparent in the reversed amplitude repeat of the englacial return after a delay of $\sim 50 \mathrm{~ms}$. This occurs at 4-6 km. Some remnants of steep shotrelated linear noise also remain evident in the data.
The transverse profile T-line (Fig. 8) was acquired upstream of the L-line. The profile is also $\sim 14 \mathrm{~km}$ long and includes a gap of $\sim 2 \mathrm{~km}$ where no data were acquired. Englacial reflectivity is observed to begin at $\sim 480 \mathrm{~m}$ above the bed ( $77 \%$ of the ice-sheet thickness). Individual horizons can be traced throughout both segments of the profile. The reflectivity is largely bed-conformable. Examples of englacial reflectivity not related to bed topography are apparent near the $1 \mathrm{~km}$ mark, and are likely inherited from upstream. There are few examples of cross-cutting structures, and those that are evident are likely the result of inadequate migration.

\section{THE ORIGIN OF ENGLACIAL REFLECTIVITY}

The origin of englacial reflectivity is best examined by considering the seismic reflection coefficient, $R$. For two layers, layer 1 overlying layer $2, R$ at normal incidence is determined by

$$
R=\frac{Z_{2}-Z_{1}}{Z_{2}+Z_{1}}
$$

where $Z_{i}=\rho_{i} V_{i}$ is the acoustic impedance of each layer, with density $\rho_{i}$ and velocity $V_{i}(i=1,2)$. We consider the two cases discussed by Bentley (1971b) and Burkett (2000), pure ice and impure ice.

\section{Impure-ice mechanisms}

Bentley (1971b) favored a moraine entrainment explanation for the englacial reflectivity observed throughout West Antarctica based on the character of the reflections commonly reverberatory and discontinuous - and on absolute and relative amplitudes. The reverberatory reflection characteristics were used to support a moraine entrainment hypothesis as pure-ice induced changes were thought to be discrete and singular. Subsequent ice-core observations show that complexity does not preclude COF as an explanation. Complex interfingered fabrics, sampled over tens to hundreds of meters, have been observed in the Byrd core (Gow and Williamson, 1976), at Siple Dome (DiPrinzio and others, 2005; Gow and Meese, 2007a) and in Greenland (Gow and others, 1997). The discontinuous nature of the englacial reflectivity was also used to

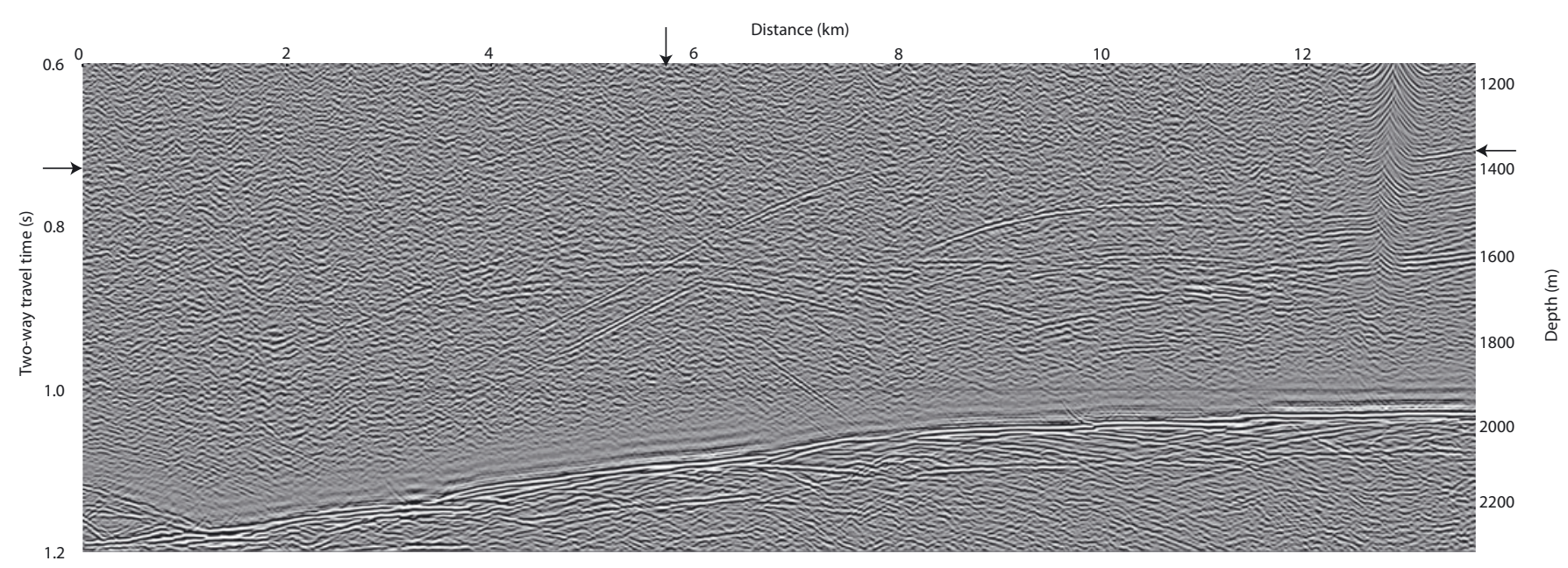

Fig. 7. Onset-region longitudinal profile (Fig. 1e; L-line for location). Flow from left to right. Englacial reflectivity is continuous on this profile for distances of up to $5 \mathrm{~km}$. The onset of englacial reflectivity is marked with horizontal arrows on the time and depth scales. Cross-cutting structures are evident and are marked with vertical arrows on the distance scale. Ghosting resulting from a peg-leg multiple path is evident in the reverse-polarity repeat of the englacial reflector between 4.5 and $6 \mathrm{~km}$. 


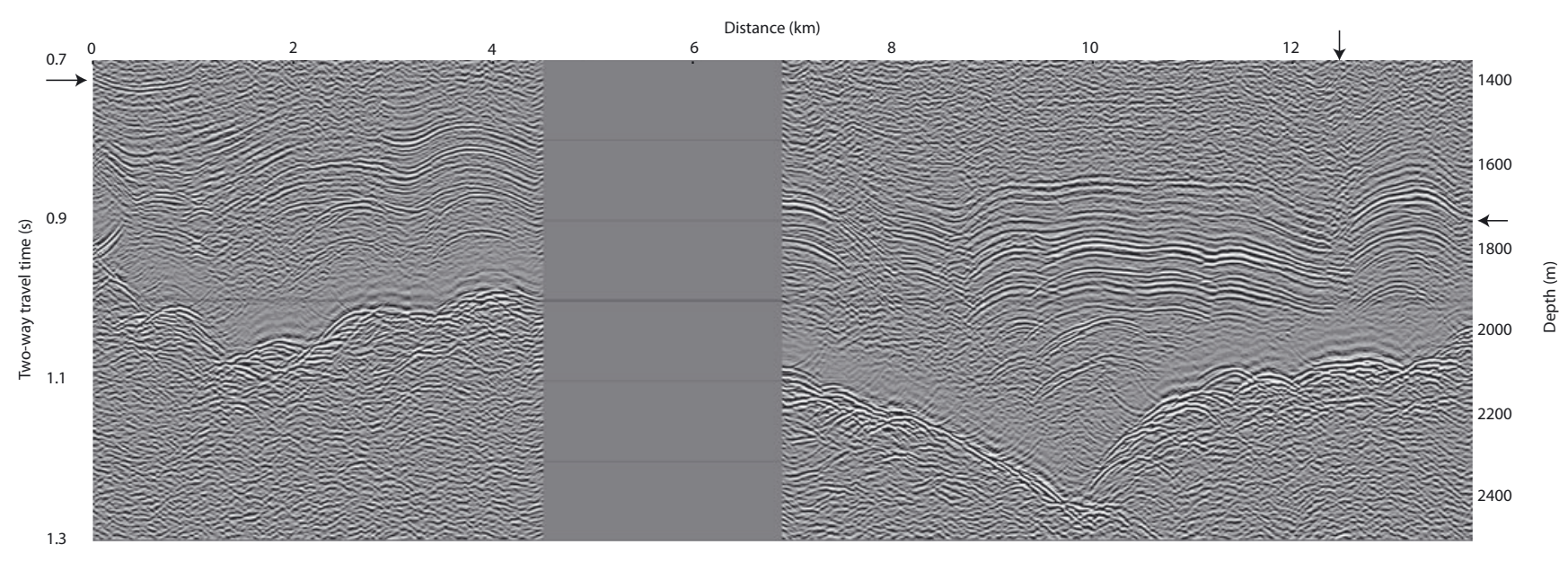

Fig. 8. Onset region transverse profile (Fig. 1e; T-line for location). Flow into the page. The onset of englacial reflectivity is marked with horizontal arrows on the time and depth scales. Englacial reflectors appear continuous across the entire profile (excluding the data gap). Structures are loosely bed-conformable, and cross-cutting structures are rare. Structure not obviously related to bed topography is marked with a vertical arrow on the distance scale.

support a moraine genesis; however, the low signal-to-noise ratios possible with the then-available technology make discontinuity unsurprising when variable shot and receiver coupling is considered. Our high-resolution, more modern data demonstrate surprisingly good continuity, within shots, between shots and between profiles (Figs 2-8). The absoluteamplitude analysis presented by Bentley (1971b), while rigorous and thorough, relied on several calibration factors including shot coupling and receiver coupling. Bentley's amplitude-ratio analysis (Bentley, 1971b) removes these effects, but introduces an assumption that the bed amplitude is well known and similar from place to place. This is not the case, and subsequent studies (e.g. Blankenship and others, 1987) have revealed the presence of soft sediments with low acoustic impedance underlying the Siple Coast ice streams. The presence of such sediments at the base of the ice sheet, as opposed to the crystalline basement rock assumed by Bentley (1971b), reduces his estimates of englacial reflection amplitudes to a magnitude capable of being caused by contrasts in COF.

Additional arguments against the impure-ice hypothesis include the following. The presence and relative abundance of bubbles or dust in ice is insufficient to directly influence the acoustic impedance to generate reflectivity (Bentley, 1971b; Röthlisberger, 1972). Also, observations of entrained material within ice cores are scarce and typically occur only within a few meters of the bed (e.g. Gow and Williamson, 1976). Interestingly, the Byrd ice core contained morainal material only in the lowest $5 \mathrm{~m}$ of the core (Gow and Williamson, 1976), which was attributed to basal freezeon. Approximately $10 \mathrm{~km}$ away from the Byrd core, Bentley (1971b) reported englacial reflectivity at $82 \%$ of the travel time to the bed, which translates to slightly less than $82 \%$ of the ice thickness of $2164 \mathrm{~m}$, or $\sim 400 \mathrm{~m}$ off the bed. In the Byrd core a marked change from fine-grained crystals with predominantly vertical fabric to coarse-grained crystals with a distributed fabric is observed at $\sim 84 \%$ of the depth to the bed (Gow and Williamson, 1976), a depth that is identical within uncertainties. Perhaps most problematic for the impure-ice hypothesis is the lack of a mechanism to transport considerable quantities of moraine up within the ice sheet. This is especially true for ice divides where the transport direction is predominantly vertically downward, rendering erosion and upwards transport of subglacial material difficult. Furthermore, the Byrd core is known to be in stratigraphic order with no gaps or insertions across the reflector depth (Blunier and Brook, 2001), inconsistent with disturbances inserting morainal material so high in the ice sheet. Even the strong vertical mixing documented in the central Greenland GRIP (Greenland Icecore Project) and GISP2 ice cores did not move morainal material high into the ice sheet, with zero or very little basal material reaching $>14 \mathrm{~m}$ above the bed (Bender and others, 2010).

\section{Pure-ice mechanisms}

In the case of pure-ice reflectivity, with no change in density, the reflection coefficient is determined by

$$
R=\frac{V_{2}-V_{1}}{V_{2}+V_{1}}
$$

Compressional wave velocity, $V_{p}$, is independent of grain size and weakly related to temperature, $T\left({ }^{\circ} \mathrm{C}\right)\left(V_{\mathrm{p}}=\right.$ $(-2.3 \pm 0.17) T+3795 \mathrm{~m} \mathrm{~s}^{-1}$; Kohnen, 1974). An exception to this relationship occurs close to the melting point, where a decrease in velocity of several hundred $\mathrm{m} \mathrm{s}^{-1}$ occurs for a warming of a few tenths of a degree (Röthlisberger, 1972). Reflectivity due to temperature gradients in pure ice is only likely to occur proximal to the melting point, and is likely to cause only one reflection event. We rule out a pureice, temperature-related cause for the englacial reflectivity we observe because (1) reflectivity occurs too high in the ice column to be attributable to ice that is close to the pressure-melting point and (2) the multiple-reflection events we observe would necessitate a temperature structure that would quickly be eliminated by high thermal gradients.

Seismic waves in ice travel up to $5 \%$ faster along the $C$-axis than perpendicular to it (Bennett, 1968; Bentley, 1971a; Röthlisberger, 1972). Figure 9 shows the velocity relationships for idealized COF distributions and ray geometries. Glacier ice can range from isotropic to nearly single-crystal anisotropy (e.g. Anandakrishnan and others, 1994), and the link between COF and velocity is well established (Bennett, 1968; Bentley, 1972; Herron and others, 1982). Abrupt velocity changes, with correspondingly abrupt changes in 

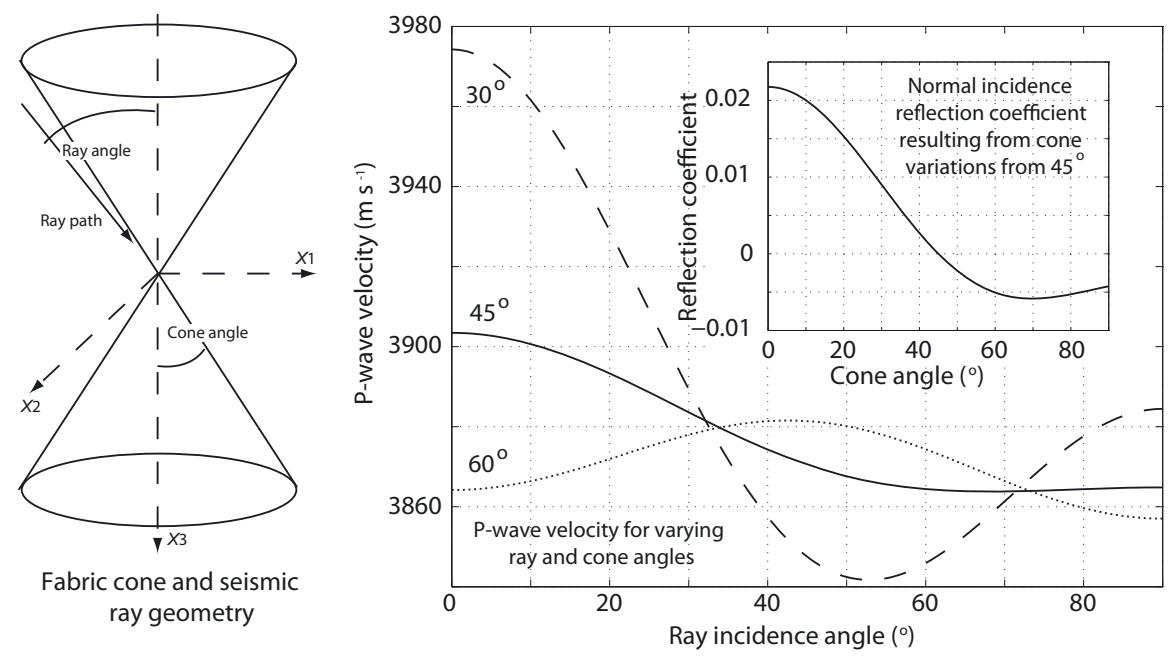

Fig. 9. Seismic anisotropy of ice. The left panel shows an idealized geometry where the $c$-axes of crystals within an ice sample are evenly distributed within a vertically oriented cone. The right panel shows P-wave velocities resulting from various cone and ray geometries. The inset in the right panel shows the normal incidence reflection coefficient resulting from contrasts in cone angle from $\sim 45^{\circ}$. (Adapted from Bennett, 1968; Blankenship and Bentley, 1987.)

$C$-axis fabrics, have been observed in ice cores (e.g. Herron and others, 1985; Gow and Meese, 2007b), but not as frequently as our observations and those of Bentley (1971b) might imply. We suggest this is due to the bias of sampling towards ice divides and the progressive development of COF with ice-sheet deformation.

\section{AMPLITUDE ANALYSIS}

Seismic amplitude analysis can be used to estimate the contrast in acoustic properties at a reflection interface, thus constraining the types of material occurring at depth. The seismogram records seismic energy, which originates from the source, spreads and attenuates, and reflects off contrasts in acoustic properties at depth. The reflected portion of seismic energy continues to spread and attenuate as it propagates back to the surface. To estimate the contrast in acoustic properties occurring at the englacial reflection horizon we follow the methodology outlined by Röthlisberger (1972), Holland and Anandakrishnan (2009) and Peters (2009). Data suitable for our form of amplitude analysis contain an englacial reflector with amplitude $A_{\mathrm{E}}$, a bed return, $A_{1}$, and a long-path multiple of the bed return, $A_{2}$. These data must be uncontaminated by shot-generated or other noise and must be from a region of relatively flat topography. Suitable data are available at down-Thwaites, up-Thwaites and at the onset of Bindschadler Ice Stream. For an attenuation estimate we use the direct arrival energy, $B_{i}$, of Holland and Anandakrishnan (2009):

$$
B_{i}=A_{0} \gamma_{i} \mathrm{e}^{-\alpha s_{i}},
$$

where subscript $i$ denotes the receiver index, $\gamma$ the path amplitude factor, $\alpha$ the attenuation factor and $s$ the path length. Rearranging Equation (1), an estimate of attenuation, $\alpha$, can be obtained from the slope of a linear regression of $s_{i}$ against $\ln \left(B_{i} / \gamma_{i}\right)$. This method requires that the data included in the regression are from sufficiently high offsets that the main difference in the paths is the additional travel path within the ice rather than in the firn. Path lengths, $s_{i}$, and path amplitude factors, $\gamma_{i}$, were calculated using ray-tracing through one-dimensional velocity models. The velocity models were estimated using Herglotz-Weichert inversion (e.g. Shearer, 2009) of shallow refraction data acquired at each study location. Path amplitude factors for the direct arrivals used a simplified $1 / s_{i}$ approximation due to the complexity of the direct-path $\gamma$. All other path amplitude factor estimates were calculated using an energyconservation ray-tube approach (e.g. Medwin and Clay, 1977). Our attenuation estimate of $\alpha=0.27 \mathrm{~km}^{-1}$ is in keeping with those of previous studies (Bentley and Kohnen, 1976), although we note that this is likely our main source of uncertainty.

The seismic shot size, $A_{0}$, was estimated using the primary and first long-path multiple bed return $\left(A_{1}\right.$ and $A_{2}$, respectively). Following Holland and Anandakrishnan (2009) we estimate the source magnitude using angles within $10^{\circ}$ of normal incidence using

$$
A_{0}=\frac{A_{1}^{2}}{A_{2}} \frac{\gamma_{2}}{\gamma_{1}^{2}} \mathrm{e}^{\alpha\left(2 d_{1}-d_{2}\right)},
$$

where $d_{1}$ and $d_{2}$ denote the path length of the primary bed reflection and long-path bed multiple, respectively. After calculation of the source amplitude, the englacial reflection coefficient, $R_{\mathrm{E}}$, and its variation with angle of incidence, $\Theta$, is calculated using:

$$
R_{\mathrm{E}}(\Theta)=\frac{A_{\mathrm{E}}}{A_{0}} \frac{1}{\gamma_{\mathrm{E}}} \mathrm{e}^{\alpha d_{1}} .
$$

We first estimate the englacial reflection coefficient for a long-offset profile acquired during the down-Thwaites 2007/08 survey. At down-Thwaites, long-offset surveying targeted a $480 \mathrm{~m}$ long section of the bed. During surveying, the source and receivers remained symmetrical about the center of the survey regardless of their separation offset. Englacial reflectivity was traced out to offsets of $\sim 40^{\circ}$ before becoming masked by source-related linear noise. The variation of amplitude with angle of incidence due to a contrast in acoustic properties is described by the Zoeppritz equations (e.g. Aki and Richards, 1980). We calculate the contrast in properties across the englacial reflection horizon using an optimization search of the Zoeppritz-equation approximations of Aki and Richards (1980). We assume the 

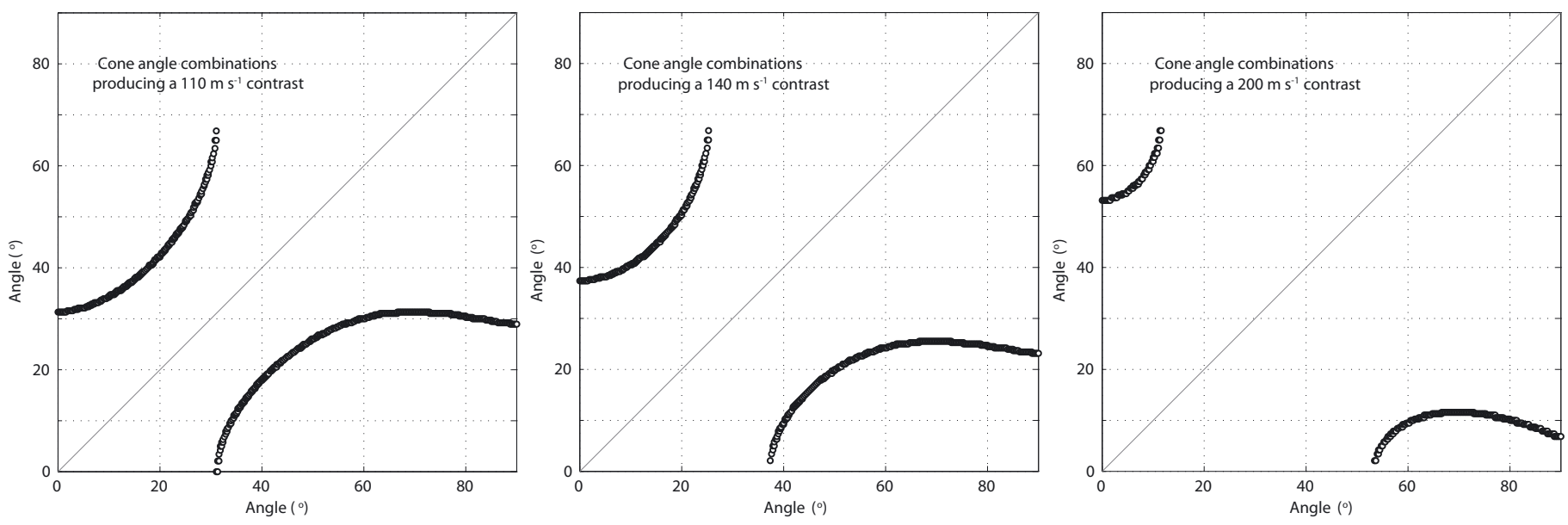

Fig. 10. Cone angle combinations resulting in the velocity contrasts given in Table 3 .

impedance contrast is due to a contrast in velocity alone (see previous section for discussion) and that the shear-wave velocity is half the P-wave velocity (equivalent to a Poisson's ratio $=1 / 3$ ). As amplitude information is non-uniquely related to velocity, we are unable to constrain the absolute velocities but are able to constrain the velocity contrast. Additional uncertainty is introduced by the assumption of isotropy in the Zoeppritz equations. The presence of anisotropy in the ice sheet will cause the variation of amplitude with angle to differ from that of an isotropic medium (Rüger, 1997); however, the relatively weak elastic anisotropy of ice (Thomsen, 1986) results in only slight differences between anisotropic and isotropic treatments at the incidence angles we report here.

We determine the velocity contrast occurring across the englacial reflection horizon at down-Thwaites to be $110 \pm 40 \mathrm{~m} \mathrm{~s}^{-1}$ (Table 3). We perform the same amplitude analysis on a much shorter profile at our upstream Thwaites camp. At this location the velocity contrast is constrained to be $200 \pm 170 \mathrm{~m} \mathrm{~s}^{-1}$. At the onset region of Bindschadler Ice Stream we calculate the amplitude of the englacial reflector for 26 different shots. Combining these amplitude picks in a single optimization search results in an estimate of velocity contrast for the onset region of $140 \pm 50 \mathrm{~m} \mathrm{~s}^{-1}$. We estimate our uncertainties using a range of attenuation estimates between $\alpha=0.2$ and $0.4 \mathrm{~km}^{-1}$. Cone angle combinations capable of causing these velocity contrasts are shown in Figure 10. Our amplitude analysis uses rms amplitudes, so we lose polarity information. However, observations of raw data show that the englacial reflection horizons used in our amplitude analysis have a negative polarity, indicating a downward transition from a faster to a slower velocity. We pick only the most prominent englacial reflector, so the possibility that changes from slower to faster velocities occur remains.

\section{DISCUSSION}

Observations of englacial reflectivity are widespread in West Antarctica and most likely result from abrupt changes in COF. This is supported by the following. Firstly, observations of englacial reflectivity are consistent with current knowledge of COF development in ice sheets. Secondly, englacial reflectivity caused by COF contrasts requires the simplest genesis, especially at ice divides. Lastly, amplitude analysis shows that observations of englacial reflectivity can be explained by COF changes alone. We begin this discussion by expanding upon these points.

At and near ice divides, direct observations show relatively simple COF structures resulting primarily from the gradual burial and strain of ice. Ice-divide crystal development can be loosely split into three depth zones (e.g. Alley, 1992; Thorsteinsson and others, 1997). In the uppermost zone, grain size increases linearly and COF cone angles gradually tighten from an approximately random distribution to a vertically oriented cone distribution. Below some intermediate depth, polygonization balances crystal growth, resulting in a relatively constant texture (Alley, 1992), while $c$-axes continue to rotate under vertical compression and bed-parallel simple shear, leading to a progressive tightening of the vertically oriented COF (Alley, 1988). This vertical clustering hardens the ice against vertical compression but softens it for simple shear (Budd and Jacka, 1989). In the lowermost zone, the upper depth of which seems largely temperature-dependent (e.g. Gow and Williamson, 1976; Thorsteinsson and others, 1997), dynamic recrystallization fabrics and textures dominate as new fastgrowing crystals are formed with $c$-axes at high angles to the vertical. Some complexity is observed in ice-core measurements. For example, at GISP2, located $28 \mathrm{~km}$ west of Greenland's summit, Alley and others (1997) report folding and overturning beginning at a depth of $70 \%$ of the icesheet thickness. Alley and others (1997) also report planes of grains cross-cutting the core. These 'stripes' consist of $c$-axes largely parallel to the stripe plane for those within $\sim 50^{\circ}$ of the vertical (Alley and others, 1997). (We note that these stripes are below the resolution of our seismic methods.) In West Antarctica, at Siple Dome, Gow and

Table 3. Mean reflection amplitudes (with $1 \sigma$ values in parentheses) and corresponding best-fitting velocity contrasts

\begin{tabular}{lcc} 
Location & Average reflection coefficient & $\begin{array}{c}\text { Velocity contrast } \\
\mathrm{m} \mathrm{s}^{-1}\end{array}$ \\
\hline Down-Thwaites & $0.013(0.005)$ & $110 \pm 40$ \\
Up-Thwaites & $0.025(0.010)$ & $200 \pm 170$ \\
Onset-D & $0.017(0.003)$ & $140 \pm 50$ \\
\hline
\end{tabular}


Meese (2007a) report the occurrence of a thick zone of tightly clustered and vertically oriented $c$-axis orientations associated with an abundance of tephra particles at $\sim 70-80 \%$ of the ice thickness. Within this zone, Gow and Meese (2007b) also note the presence of alternating bands of contrasting COFs.

When comparing our seismic observations with current knowledge of COF, the most obvious association is the onset of recrystallization, which is likely responsible for a single prominent and continuous reflection horizon observed proximal to the bed. A corollary of this, if one takes into account the conditions conducive to recrystallization (Gow and Williamson, 1976; DiPrinzio and others, 2005), is that our seismic observations contain information on the temperature structure and strain history of the ice sheet. Complex COF structures observed in ice cores (e.g. Alley and others, 1997) go some way towards explaining the complicated and often cross-cutting patterns we observe in our seismic data. The existence of complex COF structures is also supported by studies showing the development of COF with strain (Alley, 1988; Budd and Jacka, 1989; Wilson and others, 2003). Observations of abrupt changes in COF associated with impurities (Gow and Meese, 2007b) may also be responsible for some of the numerous, and relatively continuous, reflection horizons we observe.

A proposed alternate means of generating englacial reflectivity within ice sheets requires large-scale mass transport of basal material (Bentley, 1971a). While basal material is certainly eroded (Hallet and others, 1996), and basal accretion can lead to such material being incorporated into an ice sheet, we consider these processes unlikely to produce the distinct and continuous reflectivity observed high above the ice-sheet base. (Consider the end-member example of an ice divide, where the flow direction is predominantly vertical and down, and yet englacial reflectivity is observed (Fig. 2)). Additionally, the unusual englacial reflection patterns observed upstream of bed features (Fig. 3) do not support entrainment as an explanation. A bedrock obstacle causes enhanced strain up-glacier of it, and this may cause a change in COF; however, a bedrock obstacle cannot serve as a source for morainal material in ice that is well up-glacier of the obstacle. The possibility remains that some entrainment of englacial materials occurs and is seismically resolvable, but we consider this to be a much rarer phenomenon than COF contrasts.

Amplitude analysis of seismic data is consistent with a COF origin for englacial reflectivity (Table 3; Figs 9 and 10); however, more conclusive evidence might be provided by a targeted study of englacial reflectivity using three-component sensors and recently proposed acquisition methodologies (Holland and Anandakrishnan, 2009). Ultimately, direct sampling of a zone of englacial reflectivity by way of coring and thin-section analysis will provide the necessary ground truth of the COF-contrast origin of englacial seismic reflectivity. We do, however, note that the measurement of englacial reflectivity requires good signal-to-noise ratios. (The englacial reflection coefficient is approximately an order of magnitude less than the bed return.) The absence of englacial reflectivity in a seismic section should therefore not be taken as conclusive proof of the absence of abrupt changes in COF. This is especially the case at ice divides, which commonly correspond to locations of deep firn/ice transitions, resulting in shots being placed at shallower relative depths in the density/depth profile compared with off-divide sites. This placement results in relatively poorer shot coupling, and more energy is trapped within the lowerdensity firn layer, resulting in stronger linear (coherent) noise.

Our observations add an extra dimension to the current view of COF in ice sheets. As ice flows towards the coast, COF structures increase in complexity. Englacial COF structures generally mimic bed topography, with long-spatial-wavelength features in the direction of flow, and short-wavelength features perpendicular to flow. It is also common to observe more than one reflection horizon, and cross-cutting structures are evident (Figs 3-8). Englacial COF structures are well developed by the time ice has flowed to the onset region of the Bindschadler Ice Stream, and display increasing complexity with downstream distance on Thwaites Glacier. The high frequency of the reflections $(\sim 150-200 \mathrm{~Hz})$ indicates that the transition between different fabric patterns occurs over a few tens of meters at most. The presence of several reflection horizons indicates either that a stepwise change in COF occurs, or that COF alternates between different states (e.g. narrow cone to distributed cone and back again). This latter case was proposed by Matsuoka and others (2003) to explain their multipolarization radar observations from East Antarctica. Stepwise varying or alternating fabrics are most easily explained by invoking variable levels of impurity loading and subsequent differences in fabric development. Variable impurity levels lead to variable COFs, as dissolved impurities impinge grain-boundary migration (Alley and others, 1986a,b). For example, Gow and Meese (2007b) observe fine-grained impure ice with a strong vertical fabric orientation subjacent to coarse-grained pure ice with a distributed fabric. The influence of impurities on the creep of ice and grain-boundary migration is not straightforward, with dependencies on particle size and concentrations (Song and others, 2005). However, variations in impurity content, which may not be realized as COF variations at an ice divide, may lead to seismically resolvable COF contrasts, due to different responses to strain.

The link between COF and viscosity makes these observations important for ice dynamics. Typically, in the absence of sliding, the shape of the velocity/depth function in a glacier is smoothly varying with a fairly constant velocity in the upper glacier and an increasing velocity/depth gradient as the bed is approached. Contrasts in COF will promote steps in the velocity/depth function as zones less prone to shearing are juxtaposed with zones more favorably oriented. COF contrasts within the ice are also likely to focus deformation resulting in behavior such as the deep thrusting events observed in tiltmeter data on Jakobshavn Isbræ (Lüthi and others, 2003). At Law Dome, East Antarctica, Budd and Jacka (1989) found that the majority of shearing is accommodated in the third deepest quarter of the ice sheet. Typically, this zone exhibits strong clustering of COF $c$-axes about the vertical axis. In the bottom quarter of the ice sheet, where we image most englacial reflectivity, Budd and Jacka (1989) noted that the basal ice exhibits variable strain due to its interaction with subglacial topography. Such interaction with subglacial topography is evident in our data (e.g. Fig. 3), as it is in the findings of Fujita and others (1999). In Figure 3, each major bed feature has a corresponding englacial reflector, originating from upstream, and finishing near the bed feature. Upstream of bedrock features, longitudinally compressive stresses are added to the stress tensor, while downstream of 
such features longitudinal extension occurs. These variations in the stress regime, all of which are occurring in relatively warm, recrystallizing ice, may be manifesting themselves in COF structures.

\section{SUMMARY AND CONCLUSIONS}

Active-source seismic imaging provides insight into the deformation of ice sheets. Seismic imaging of contrasts in COF offers us an extra dimension in which to investigate the role of crystal fabric in the flow of ice sheets over scales of tens to hundreds of kilometers. The major findings and conclusions of this study can be summarized as follows:

Englacial seismic reflectivity observed throughout West Antarctica is due to changes in the COF of ice. A COF origin for englacial reflectivity is consistent with current knowledge of COF from ice cores and laboratory studies. A COF origin is also supported by arguments regarding the mechanism of generation of englacial seismic reflectivity and amplitude analysis of seismic reflection data.

COF patterns within the ice sheet change abruptly and often. These changes are mostly observed in the bottom quarter of the ice sheet. Large-scale COF structures are associated with bed topography, but not always in a straightforward manner. COF structures increase in complexity with distance from ice divides. Because of this, the role and complexity of COF within ice sheets is likely to be greater than that implied by ice cores obtained at or near ice divides.

COF contrasts are likely caused by the combined effects of strain, impurities and temperature, all of which play a role in the recrystallization of ice. Seismic imaging of englacial COF structures may offer additional insights into the interaction between ice sheets and the substrate over which they flow.

Knowledge of COF has direct implications for the predictive modeling of polar ice sheets. The role of COF in ice dynamics is likely most important in regions where englacial deformation dominates, and is likely less important once the ice transitions into a regime where sliding or subglacial deformation dominates.

These observations await ground truthing. Ground truthing should combine active-source seismology with ice coring, borehole logging and thin-section analysis. Such a study should occur in an area known to exhibit abundant englacial reflectivity. Once ground truthed, active-source seismic observations will allow the extrapolation of borehole observations over large distances and contribute to our understanding of how ice sheets deform and interact with the underlying bed.

\section{ACKNOWLEDGEMENTS}

This work was made possible by the US National Science Foundation and the Center for Remote Sensing of Ice Sheets (CReSIS) (NSF-OPP-0424589 (CReSIS), 0539578 (R.B.A.)) along with field support from Raytheon Polar Services Company. H.J.H. is grateful for the generous support of the Alan Eggers Endowment. Active-source seismic acquisition is an arduous enterprise and we are grateful for the assistance of P. Braddock, K. Christianson, R. Greschke, J. MacGregor, A. Mironov, A. Morton, M. Nolan, S. O'Neel, A. Smith, D. Voigt, J.P. Winberry and L. Zoet. We thank I. Joughin for velocity data. The manuscript was improved by the reviews of T.H. Jacka and an anonymous reviewer, and by discussions with R. Dadić and A. Mackintosh.

\section{REFERENCES}

Aki, K. and P.G. Richards. 1980. Quantitative seismology. Second edition. Sausalito, CA, University Science Books.

Alley, R.B. 1988. Fabrics in polar ice sheets: development and prediction. Science, 240(4851), 493-495.

Alley, R.B. 1992. Flow-law hypotheses for ice-sheet modeling. J. Glaciol., 38(129), 245-256.

Alley, R.B., J.H. Perepezko and C.R. Bentley. 1986a. Grain growth in polar ice: I. Theory. J. Glaciol., 32(112), 415-424.

Alley, R.B., J.H. Perepezko and C.R. Bentley. 1986b. Grain growth in polar ice: II. Application. J. Glaciol., 32(112), 425-433.

Alley, R.B., A.J. Gow, D.A. Meese, J.J. Fitzpatrick, E.D. Waddington and J.F. Bolzan. 1997. Grain-scale processes, folding and stratigraphic disturbance in the GISP2 ice core. J. Geophys. Res., 102(C12), 26,819-26,830.

Anandakrishnan, S. 1996. Seismic reflections from an internal layer: fabric change or moraine? Eos, 77(17), S150, Spring Meet. Suppl.

Anandakrishnan, S., J.J. Fitzpatrick, R.B. Alley, A.J. Gow and D.A. Meese. 1994. Shear-wave detection of asymmetric C-axis fabrics in the GISP2 ice core, Greenland. J. Glaciol., 40(136), 491-496.

Bender, M.L., E. Burgess, R.B. Alley, B. Barnett and G.D. Clow. 2010. On the nature of the dirty ice at the bottom of the GISP2 ice core. Earth Planet. Sci. Lett., 299(3-4), 466-473.

Bennett, H.F. 1968. An investigation into velocity anisotropy through measurements of ultrasonic-wave velocities in snow and ice cores from Greenland and Antarctica. (PhD thesis, University of Wisconsin-Madison.)

Bentley, C.R. 1971a. Seismic anisotropy in the West Antarctic ice sheet. In Crary, A.P., ed. Antarctic snow and ice studies II. Washington, DC, American Geophysical Union, 131-177.

Bentley, C.R. 1971b. Seismic evidence for moraine within the basal Antarctic ice sheet. In Crary, A.P., ed. Antarctic snow and ice studies II. Washington, DC, American Geophysical Union, 89129.

Bentley, C.R. 1972. Seismic-wave velocities in anisotropic ice: a comparison of measured and calculated values in and around the deep drill hole at Byrd Station, Antarctica. J. Geophys. Res., 77(23), 4406-4420.

Bentley, C.R. and J.W. Clough. 1972. Antarctic subglacial structure from seismic refraction measurements. In Adie, R.J., ed. Antarctic geology and geophysics. Symposium on Antarctic Geology and Solid Earth Geophysics, 6-15 August 1970, Oslo. Oslo, Universitetsforlaget, 683-691.

Bentley, C.R. and H. Kohnen. 1976. Seismic refraction measurements of internal friction in Antarctic ice. J. Geophys. Res., 81 (8), 1519-1526.

Bentley, C.R. and N.A. Ostenso, 1961. Glacial and subglacial topography of West Antarctica. J. Glaciol., 3(29), 882-911.

Blankenship, D.D. and C.R. Bentley. 1987. The crystalline fabric of polar ice sheets inferred from seismic anisotropy. IAHS Publ. 170 (Symposium at Vancouver 1987 - The Physical Basis of Ice Sheet Modelling), 17-28.

Blankenship, D.D., C.R. Bentley, S.T. Rooney and R.B. Alley. 1987. Till beneath Ice Stream B. 1. Properties derived from seismic travel times. J. Geophys. Res., 92(B9), 8903-8911.

Blunier, T. and E.J. Brook. 2001. Timing of millennial-scale climate change in Antarctica and Greenland during the last glacial period. Science, 291(5501), 109-112. 
Budd, W.F. and T.H. Jacka. 1989. A review of ice rheology for ice sheet modelling. Cold Reg. Sci. Technol., 16(2), 107-144.

Burkett, P.G. 2000. Ice fabric and active seismology: an investigation and interpretation in central West Antarctica. (MSc thesis, Pennsylvania State University.)

Conway, H. and L.A. Rasmussen. 2009. Recent thinning and migration of the Western Divide, central West Antarctica. Geophys. Res. Lett., 36(12), L12502. (10.1029/2009GL038072.)

DiPrinzio, C.L., L.A. Wilen, R.B. Alley, J.J. Fitzpatrick, M.K. Spencer and A.J. Gow. 2005. Fabric and texture at Siple Dome, Antarctica. J. Glaciol., 51(173), 281-290.

Eisen, O., I. Hamann, S. Kipfstuhl, D. Steinhage and F. Wilhelms. 2007. Direct evidence for continuous radar reflector originating from changes in crystal-orientation fabric. Cryosphere, 1(1), $1-10$.

Fujita, S. and 6 others. 1999. Nature of radio-echo layering in the Antarctic ice sheet detected by a two-frequency experiment. J. Geophys. Res., 104(B6), 13,013-13,024.

Gow, A.J. and D.A. Meese. 2007a. The distribution and timing of tephra deposition at Siple Dome, Antarctica: possible climatic and rheologic implications. J. Glaciol., 53(183), 585-596.

Gow, A.J. and D.A. Meese. 2007b. Physical properties, crystalline textures and $c$-axis fabrics of the Siple Dome (Antarctica) ice core. J. Glaciol., 53(183), 573-584.

Gow, A.J. and T. Williamson. 1976. Rheological implications of the internal structure and crystal fabrics of the West Antarctic ice sheet as revealed by deep core drilling at Byrd Station. Geol. Soc. Am. Bull., 87(12), 1665-1677.

Gow, A.J. and 6 others. 1997. Physical and structural properties of the Greenland Ice Sheet Project 2 ice cores: a review. J. Geophys. Res., 102(C12), 26,559-26,575.

Hallet, B., L.E. Hunter and J. Bogen. 1996. Rates of erosion and sediment evacuation by glaciers: a review of field data and their implications. Global Planet. Change, 12(1-4), 213-235.

Herron, S.L., C.C. Langway, Jr and K.A. Brugger. 1985. Ultrasonic velocities and crystalline anisotropy in the ice core from Dye 3, Greenland. In Greenland ice core: geophysics, geochemistry, and the environment. Washington, DC, American Geophysical Union, 23-31.

Hobbs, P.V. 1974. Ice physics. Oxford, etc., Clarendon Press.

Holland, C.W. and S. Anandakrishnan. 2009. Subglacial seismic reflection strategies when source amplitude and medium attenuation are poorly known. J. Glaciol., 55(193), 931-937.

Hooke, R.LeB. 1973. Structure and flow in the margin of the Barnes Ice Cap, Baffin Island, NWT, Canada. J. Glaciol., 12(66), 423-438.

Horgan, H.J. and 6 others. 2008. Complex fabric development revealed by englacial seismic reflectivity: Jakobshavn Isbræ, Greenland. Geophys. Res. Lett., 35(10), L10501. (10.1029/2008GL033712.)

Joughin, I. and 6 others. 2009. Basal conditions for Pine Island and Thwaites Glaciers, West Antarctica, determined using satellite and airborne data. J. Glaciol., 55(190), 245-257.

Kohnen, H. 1974. The temperature dependence of seismic waves in ice. J. Glaciol., 13(67), 144-147.
Lüthi, A., M. Funk and A. Iken. 2003. Indication of active overthrust faulting along the Holocene-Wisconsin transition in the marginal zone of Jakobshavn Isbræ. J. Geophys. Res., 108(B11), 2543. (10.1029/2003JB002505.)

Matsuoka, K. and 6 others. 2003. Crystal-orientation fabrics within the Antarctic ice sheet revealed by a multi-polarization-plane and dual frequency radar survey. J. Geophys. Res., 108(B10), 2499. (10.1029/2002JB002425.)

Medwin, H. and C.S. Clay. 1977. Acoustical oceanography: principles and applications. New York, Wiley.

Peters, L.E. 2009. A seismic investigation of basal conditions in glaciated regions. (PhD thesis, Pennsylvania State University.)

Peters, L.E. and 6 others. 2006. Subglacial sediments as a control on the onset and location of two Siple Coast ice streams, West Antarctica. J. Geophys. Res., 111(B1), B01302. (10.1029/2005JB003766.)

Peters, L.E., S. Anandakrishnan, R.B. Alley and A.M. Smith. 2007. Extensive storage of basal meltwater in the onset region of a major West Antarctic ice stream. Geology, 35(3), 251-254.

Rigsby, G.P. 1958. Effect of hydrostatic pressure on velocity of shear deformation on single ice crystals. J. Glaciol., 3(24), 273-278.

Ronen, J. and J.F. Claerbout. 1985. Surface-consistent residual statics estimation by stack-power maximization. Geophysics, 50(12), 2759-2767.

Röthlisberger, H. 1972. Seismic exploration in cold regions. CRREL Monogr. II-A2a.

Rüger, A. 1997. $P$-wave reflection coefficients for transversely isotropic models with vertical and horizontal axis of symmetry. Geophysics, 62(3), 713-722.

Russell-Head, D.S. and W.F. Budd. 1979. Ice-sheet flow properties derived from bore-hole shear measurements combined with icecore studies. J. Glaciol., 24(90), 117-130.

Shearer, P.M. 2009. Introduction to seismology. Second edition. Cambridge, etc., Cambridge University Press.

Smith, A.M. 1996. Ice shelf basal melting at the grounding line, measured from seismic observations. J. Geophys. Res., $\mathbf{1 0 1}$ (C10), $22,749-22,755$.

Smith, A.M. 2007. Subglacial bed properties from normal-incidence seismic reflection data. J. Environ. Eng. Geophys., 12(1), 3-13.

Song, M., D.M. Cole and I. Baker. 2005. Creep of granular ice with and without dispersed particles. J. Glaciol., 51(173), 210-218.

Thomsen, L. 1986. Weak elastic anisotropy. Geophysics, 51(10), 1954-1966.

Thorsteinsson, T., J. Kipfstuhl and H. Miller. 1997. Textures and fabrics in the GRIP ice core. J. Geophys. Res., 102(C12), $26,583-26,599$.

Van der Veen, C.J. and I.M. Whillans. 1994. Development of fabric in ice. Cold Reg. Sci. Technol., 22(2), 171-195.

Wilson, C.J.L., D.S. Russell-Head and H.M. Sim. 2003. The application of an automated fabric analyzer system to the textural evolution of folded ice layers in shear zones. Ann. Glaciol., 37, 7-17.

Yilmaz, Ö. 1987. Seismic data processing. Third edition. Tulsa, OK, Society of Exploration Geophysicists. 